\title{
Es ist wieder soweit
}

Einmal im Jahr legen wir in einer Ausgabe der Keramischen Zeitschrift den Fokus auf feuerfeste Materialien und Hochtemperaturprozesse. Warum? Weil Feuerfestmaterialien die Grundlage für die Herstellung von Produkten aus Stahl, Kupfer, Aluminium, Glas und Kunststoffen sind, die ohne sie gar nicht produziert werden könnten. Naturgemäß sind die Hochtemperaturprozesse, in denen Feuerfestmaterialien eingesetzt werden, sehr energieintensiv. Das bedeutet, dass Fortschritte in der Forschung und Entwicklung von Feuerfestprodukten die Energiebilanz dieser Prozesse positiv beeinflussen können. Deshalb geben wir in dieser Ausgabe einen Einblick in die Arbeit des Instituts für Gesteinshüttenkunde der RWTH Aachen, an dem Forscher neue feuerfeste Werkstoffe entwickeln und optimieren. Wir werfen auch einen Blick nach Höhr-Grenzhausen im Westerwald, wo das European Centre for Refractories modernste Hochtemperatur-Materialprüfmethoden entwirft. Zudem widmen wir uns in unserem aktuellen Experten-Forum der Frage: Wie sieht es eigentlich mit dem Recycling von Feuerfestmaterialien aus? Und welche Hindernisse gibt es noch?
Feuerfestprodukte spielen auch bei der thermischen Abfallentsorgung eine entscheidende Rolle, wo sie einer hochkorrosiven Rauchgasatmosphäre standhalten müssen. Analysen zeigen, welche Feuerfestmaterialien das am besten können. Und dort, wo besonders hohe thermomechanische Stabilität gefragt ist, beispielsweise bei Spülkegeln oder Aufprallplatten, zeigen neue Untersuchungen, wie CAM-Phasen in spinellhaltigem Feuerfestbeton für eine zusätzliche Verbesserung der Heißfestigkeitseigenschaften sorgen können.

Zuletzt richten wir anlässlich des Röntgenjahres, das die Entdeckung von Wilhelm Conrad Röntgen vor 125 Jahren ehrt, unseren Blick auf dieses Ereignis, das nicht nur für die Medizin von enormer Bedeutung ist. Die Entdeckung der Röntgenstrahlung legte auch den Grundstein für die Roh- und Werkstoffdiagnostik. Dr. Krause war jener Pionier, der der Röntgenographie in der Keramik zum Durchbruch verhalf. Dabei sollte auch erwähnt werden: Mit der späteren Weiterentwicklung zur Hochtemperatur-Röntgenographie war es erstmals möglich, das Verhalten von Stoffen bei hohen Temperaturen zu beobachten.

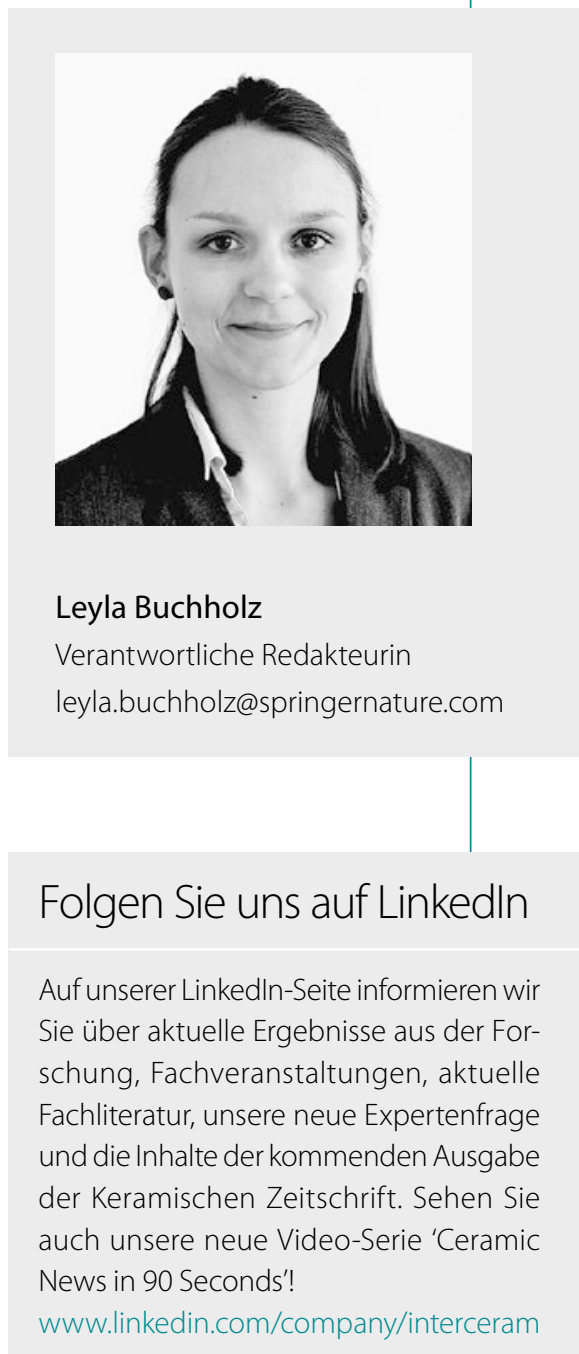

